\title{
Predictive Value of Immune Cells in the Risk of Gestational Diabetes Mellitus: A Pilot Study
}

\author{
Adnette Fagninou ${ }^{1,2}$, Magloire Pandoua Nekoua ${ }^{1}$, Salomon Ezéchiel M. Fiogbe ${ }^{2}$, \\ Kabirou Moutaïrou ${ }^{1}$ and Akadiri Yessoufou ${ }^{1 *}$ \\ ${ }^{1}$ Laboratory of Cell Biology, Physiology and Immunology, Department of Biochemistry and Cellular Biology, Faculty of \\ Sciences and Technology (FAST), Institute of Applied Biomedical Sciences (ISBA), University of Abomey-Calavi (UAC), \\ Cotonou, Benin, 2 Unité de Recherche sur les Maladies Non Transmissibles et le Cancer (UR-MNTC), Laboratory of \\ Research in Applied Biology (LARBA), Ecole Polytechnique d'Abomey-Calavi, University of Abomey-Calavi, \\ Cotonou, Benin
}

OPEN ACCESS

Edited by:

Tsvetelina Velikova,

Lozenetz Hospital, Bulgaria

Reviewed by:

Plamena Kabakchieva,

Medical University Sofia, Bulgaria

Jim Joseph,

Walter Sisulu University, South Africa

*Correspondence:

Akadiri Yessoufou

akadiri.yessoufou@gmail.com

Specialty section:

This article was submitted to

Diabetes Health Services

and Health Economics,

a section of the journal

Frontiers in Clinical

Diabetes and Healthcare

Received: 20 November 2021

Accepted: 06 January 2022

Published: 18 February 2022

Citation:

Fagninou A, Nekoua MP, Fiogbe SEM,

Moutairou $K$ and Yessoufou $A$

(2022) Predictive Value of Immune

Cells in the Risk of Gestational

Diabetes Mellitus: A Pilot Study.

Front. Clin. Diabetes Healthc. 3:819164.

doi: 10.3389/fcdhc.2022.819164
Aims: Immunological and biochemical parameters are gaining more and more importance in the prognosis of diabetes and its complications. Here, we assessed the predictive power of immune cells correlated with biochemical parameters in gestational diabetes mellitus (GDM).

Materials and Methods: Immune cells and serum biochemical parameters were determined in women with GDM and pregnant controls. Receiver operating characteristics (ROC) curve analyses were conducted to assess the optimal cutoff and value of ratios of immune cells to biochemical parameters for predicting GDM.

Results: Blood glucose, total cholesterol, LDL-cholesterol and triglycerides were significantly increased whereas HDL-cholesterol decreased in women with GDM compared to pregnant controls. Glycated hemoglobin, creatinine, transaminase activities did not significantly differ between both groups. Total leukocyte, lymphocyte and platelet numbers were significantly high in women with GDM. Correlation tests showed that ratios of lymphocyte/HDL-C, monocyte/HDL-C and granulocyte/HDL-C were significantly higher in women with GDM than in pregnant controls $(p=0.001$; $p=0.009$ and $p=0.004$ respectively). Women with a lymphocyte/HDL-C ratio greater than 3.66 had a 4 -fold increased risk of developing GDM than those with lower ratios (odds ratio 4.00; 95\% Cl: $1.094-14.630 ; p=0.041$ ).

Conclusion: Our study showed that ratios of lymphocyte, monocyte and granulocyte to HDL-C might represent valuable biomarkers for GDM and in particular, lymphocyte/HDL$\mathrm{C}$ ratio exhibited a strong predictive power for GDM risk.

Keywords: immune cells, biochemical parameters, gestational diabetes mellitus, predictive value, lymphocyte, HDL-cholesterol 


\section{INTRODUCTION}

One of the major concerns of researchers is to find biological or clinical factors with prognostic or early diagnostic value of diseases in order to strengthen or improve prevention rather than cure. In this context, little is known about the use of immunological and/or biochemical parameters in the prediction of gestational diabetes mellitus (GDM) (1,2). Recently, we investigated the modulation of immune cell frequencies in gestational diabetes, and found that gestational diabetes mellitus (GDM) modulated the frequencies of total CD3+ and CD4+ T and B cells, suggesting that immune cells could play specific role in the prognosis of this disease (3). GDM is defined as glucose intolerance arising for the first time during pregnancy with or without remission after the end of pregnancy $(4,5)$. GDM, as one of major endocrine abnormalities, is the most common metabolic disease during pregnancy and its incidence is increasing worldwide $(4,5)$. The global prevalence of GDM varies from 1 to $28 \%$ depending on population characteristics, screening methods, and diagnostic criteria (6-8) with a great percentage reported in low and middle-income countries, where access to maternal care is often limited (9). Sedentary and modern lifestyle in developing countries contribute to the increased prevalence of GDM (10, 11).

Evidently, immunological parameters including immune cell subpopulations and cytokines have been designated as predictors of endothelial dysfunction and inflammation (12). Likewise, we have recently reported that immune cell frequencies, including neutrophils, eosinophils, monocytes, NK cells, and lymphocytes, can be modulated in type 1 diabetes and type 2 diabetes whether associated with pregnancy or not, suggesting that these cells can play important roles in the pathogenesis of this disease, on the one hand $(3,13,14)$. On the other hand, we have reported that GDM can induce disruption of several biochemical and immunological parameters $(3,15,16)$. Additionally, we have reported that biochemical parameters, including glycaemia, triglycerides (TG), high density lipoprotein-cholesterol (HDLC), total cholesterol (TC), low density lipoprotein-cholesterol (LDL-C), known as metabolic biomarkers, are modulated during GDM and macrosomia (15, 17-20). Interestingly in the same way, several studies have found that immune parameters, including lymphocytes, neutrophils, monocytes, platelets, and the ratios between these cells and HDL-C, may be related to metabolic syndrome and atherosclerotic processes, as potential indicators of prothrombotic and pro-inflammatory states (2124). Consequently, early diagnosis of gestational diabetes, based on biochemical and immunological parameters, could be crucial to anticipate the care of pregnant diabetic women and thus, prevent the wide range of adverse consequences on the offspring, including macrosomia, fetal death, prematurity, birth trauma, respiratory distress syndrome, obesity, impaired glucose tolerance, and type 2 diabetes in adulthood $(15,20)$. Evidently, biochemical parameters can be easily determined in plasma and immune parameters can be easily measured from peripheral blood. Biochemical and immunological indicators, as discussed above, can be used as potential markers to predict GDM. Therefore, the principal objective of this study is to determine whether immune cells could be correlated with biochemical parameters to assess their predictive value for GDM.

\section{MATERIALS AND METHODS}

\section{Study Participants}

In this cross-sectional and descriptive study, two hundred and forty-six (246) pregnant women were firstly enrolled by specialist clinicians of the department of gynecology and obstetrics three national hospital centers in southern Benin. This sample size was calculated based on Dagnelie's formula. Based on inclusion criteria including absence of preexisting type 1 or type 2 diabetes, infectious diseases including hepatitis, HIV and malaria after blood sample tests, 210 pregnant women, aged from 19 to 43 years, were selected and then screened for GDM (see protocol below). Anthropometric and socio-demographic data, risk factors and family history associated with diabetes were recorded and presented in Table 1.

The study was conducted in accordance with the Declaration of Helsinki 1964 (as revised in Edinburgh 2000) and was approved by the Ethics Committee on Research of the Institute of Applied Biomedical Sciences of Cotonou, Benin under the number Dec.n ${ }^{\circ} 100 / C E R / I S B A-2016$. Prior to enrollment, written consent was obtained from each participant who were informed of the study aim. The privacy rights of human subjects were observed.

\section{Screening of Gestational Diabetes Mellitus}

Gestational diabetes mellitus was diagnosed in pregnant women following the protocol of the International Association of Diabetes and Pregnancy Study Group (IADPSG) (25). Briefly, women between 24 and 28 weeks of gestation after overnight fasting were submitted to an oral glucose tolerance test (OGTT) and given 75 grams of glucose. Subjects were declared as positive for GDM when overnight fasting plasma glucose was $\geq 92 \mathrm{mg} / \mathrm{dL}$ (5.1 $\mathrm{mmol} / \mathrm{L})$, or 1 -hour OGTT plasma glucose level was $\geq 180$ $\mathrm{mg} / \mathrm{dL}(10.0 \mathrm{mmol} / \mathrm{L})$, or 2-hours OGTT plasma glucose level was $\geq 153 \mathrm{mg} / \mathrm{dL}(8.5 \mathrm{mmol} / \mathrm{L})$.

The GDM screening revealed that 25 pregnant women have gestational diabetes, representing a percentage of $11.90 \%$, and considered as the cases' group. Pairing of these 25 newly GDM diagnosed women with non-diabetic pregnant women, according to age, body mass index and gestational age, allowed us to select 35 pregnant women without GDM, and considered as control group. Therefore, both groups of participants, twenty-five women with GDM and thirty-five age-matched and body mass index-matched and gestational age-matched pregnant controls were selected and submitted for blood collection and biochemical and immunological assays.

\section{Blood Samples}

Blood samples were collected from each selected participant in appropriate tubes and immediately transported to the laboratory for biological assays within 2 hours. Immune parameters and glycated hemoglobin (HbAlc) were determined in 
TABLE 1 | Anthropometric data of subjects.

\begin{tabular}{|c|c|c|c|c|c|}
\hline Characteristics & \multicolumn{2}{|c|}{ Pregnant control women } & \multicolumn{2}{|c|}{ Women with GDM } & Tota \\
\hline Number of subjects & 185 & 88.10 & 25 & 11.90 & 210 \\
\hline \multicolumn{6}{|l|}{ Age (A, years) } \\
\hline$<20$ & 05 & 2.70 & 00 & 00 & 05 \\
\hline $20 \leq \mathrm{A}<30$ & 104 & 56.22 & 09 & 36 & 113 \\
\hline $30 \leq \mathrm{A}<40$ & 71 & 38.38 & 15 & 60 & 86 \\
\hline Intense & 00 & 00 & 00 & 00 & 00 \\
\hline Moderate & 136 & 73.51 & 17 & 68 & 153 \\
\hline Inadequate & 49 & 26.49 & 08 & 32 & 57 \\
\hline \multicolumn{6}{|l|}{ Menstrual cycle } \\
\hline Regular & 80 & 43.24 & 10 & 40 & 90 \\
\hline Irregular & 105 & 56.76 & 15 & 60 & 120 \\
\hline \multicolumn{6}{|l|}{ Previous disturbances } \\
\hline Miscarriage & 44 & 23.78 & 12 & 48 & 56 \\
\hline Prematurity & 07 & 3.78 & 04 & 16 & 11 \\
\hline Normal delivery & 134 & 72.43 & 09 & 36 & 143 \\
\hline
\end{tabular}

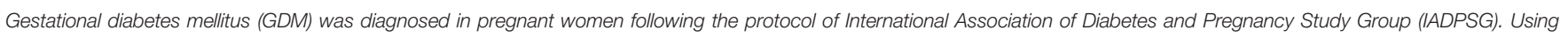

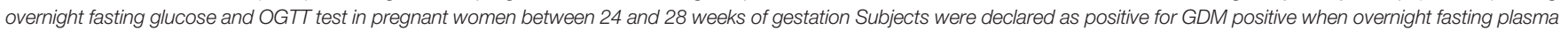
glucose was $\geq 92 \mathrm{mg} / \mathrm{dL}$ (5.1 mmol/L), or 1-hour OGTT plasma glucose level was $\geq 180 \mathrm{mg} / \mathrm{dL}$ (10.0 mmol/L), or 2-hours OGTT plasma glucose level was $\geq 153 \mathrm{mg} / \mathrm{dL}$ (8.5 mmol/L). Moderate physical activity $=30$ minutes of physical activity per day; Inadequate physical activity = insufficient or no physical activity. Regular menstrual cycle: time between successive menstruations is relatively regular and predictable. Irregular menstrual cycle: time between successive menstruations is very variable and unpredictable.

whole blood. Plasma samples were immediately used for glucose determination. Serum obtained by low-speed centrifugation was used for biochemical assays.

\section{Biochemical Assays}

Plasma glucose, total cholesterol, HDL cholesterol, triglycerides were measured by colorimetric enzymatic method using ELITech reagents (ELITech Group, Puteaux, France) according to manufacturer's instructions. LDL-cholesterol was calculated using Friedewald method (26). Total protein levels were determined by direct Biuret colorimetric method (ELITech Group, Puteaux, France). Aspartate aminotransferase (AST) and alanine aminotransferase (ALT) enzymatic activities and creatinine levels were determined by enzymatic kinetic assay (DiaSys reagents, Diagnostic Système GmbH, Germany). HbA1c concentration was calculated using a percentage of total hemoglobin, according to the manufacturer's instructions (Reference 41190, Labkit Chemelex SA, Barcelona, Spain).

\section{Determination of Immune Cells}

Immune cells were determined through the complete blood formula count using an automatic blood cell analyzer (Cell Dyn 3500, Abbott, France). These cells included total leukocytes, lymphocytes, monocytes, granulocytes and platelets (PLT).

\section{Statistical Analysis}

Data analyses were performed using Graph Pad Prism 6.0 (Graph Pad Inc., CA, USA) and $\mathrm{IBM}^{\circledR}{ }^{\circledR}$ SPSS ${ }^{\circledR}$ Statistics (version 25.0).
Values are means \pm standard deviation or medians with interquartile ranges. Student's t-test, Mann-Whitney U test and Chi-squared $(\chi 2)$ test were used when appropriate. Pearson and Spearman correlations were used to determine the association between immunological and biochemical parameters. Receiver Operating Characteristics (ROC) curve analysis was used to assess the value of immunological to biochemical parameter ratios for predicting gestational diabetes mellitus and to obtain the best cutoff value using Youden's index (sensitivity + specificity - 1). The odds ratios (ORs) are presented with 95\% confidence intervals (CI). Differences were considered significant with a twotailed $p$ value $<0.05$.

\section{RESULTS}

\section{Biochemical Parameters in Women With GDM and Pregnant Controls}

Biochemical parameters of women with GDM and pregnant controls are presented in Table 2 . We observed that plasma fasting glucose $(p<0.001)$, total cholesterol $(p=0.001)$, LDL cholesterol $(p=0.015)$, triglyceride $(p=0.035)$ and total protein $(p=0.005)$ and HDL cholesterol $(p=0.001)$ levels significantly increased, while HDL-cholesterol level decreased in women with GDM compared to pregnant controls (Table 2). However, $\mathrm{HbA1c}$ and creatinine levels, and transaminase (AST and ALT) activities did not significantly differ between the two groups of women (Table 2). 
TABLE 2 | Biochemical parameters in women with GDM and pregnant controls.

\begin{tabular}{lccc}
\hline Parameters & Pregnant control women $(\mathbf{n}=\mathbf{3 5})$ & Women with GDM (n= 25) & p-value \\
\hline Glucose (g/L) & $0.81 \pm 0.03$ & $1.16 \pm 0.04$ & 0.001 \\
HbA1c (\%) & $5.65 \pm 0.23$ & $6.47 \pm 0.48$ & 0.451 \\
TC (g/L) & $1.53 \pm 0.11$ & $2.11 \pm 0.31$ & 0.001 \\
HDL-C (g/L) & $1.21 \pm 0.15$ & $0.35 \pm 0.10$ & 0.001 \\
LDL-C (g/L) & $0.91(0.14-1.36)$ & $1.53(1.15-1.68)$ & 0.015 \\
TG (g/L) & $1.30 \pm 0.08$ & $1.63 \pm 0.18$ & 0.035 \\
AST (UI/L) & $26.63 \pm 2.64$ & $26.20 \pm 6.46$ & 0.951 \\
ALT (UI/L) & $10.50(9.75-15.25)$ & $14.00(12.00-20.00)$ & 0.425 \\
Creatinine (mg/L) & $7.30 \pm 0.45$ & $8.92 \pm 0.30$ & 0.125 \\
Total proteins (g/L) & $71.60 \pm 1.585$ & $82.23 \pm 3.32$ & 0.005 \\
\hline
\end{tabular}

TC, Total cholesterol; HDL-C, HDL cholesterol; $L D L-C, L D L$ cholesterol; TG, triglycerides. Friedewald method was used to calculate $L D L-c h o l e s t e r o l . ~ L D L-C=C T-(H D L-C+T G / 5)$ in g/l. This method is valid as the TG levels were under $4 \mathrm{~g} / \mathrm{l}$ in the present study. Aspartate aminotransferase (ASAT); Alanine aminotransferase (ALAT). Statistical analyses were performed using the Student's t-test or Mann-Whitney test. $p$ values $<0.05$ indicate significant differences. $n=25$ women with GDM, $n=35$ pregnant women without GDM as control group.

\section{Immune Cells in Women With GDM and Pregnant Controls}

Immune cell percentages of women with GDM compared to pregnant controls are shown in Figure 1. Total leukocytes ( $p=$ $0.045)$, lymphocytes $(p=0.015)$ and platelet numbers $(p=0.033)$ were significantly higher in women with GDM than in pregnant controls. However, no significant difference was observed in the numbers of monocytes and granulocytes between both groups (Figures 1, 2).

\section{Correlation Between Immune Cells and Biochemical Parameters}

In pregnant control women, the correlation tests revealed a positive correlation between blood glucose with lymphocytes $(\mathrm{r}=0.89 ; p=0.03)$ and between lymphocytes with total cholesterol ( $\mathrm{r}=0.50 ; p=0.04$ ) (Table 4). Moreover, a positive correlation was found between monocytes with triglycerides $(\mathrm{r}=$ $0.58 ; p=0.04)$. In contrast, a negative correlation was observed between monocytes and HDL-cholesterol levels ( $\mathrm{r}=-0.68 ; p=$ 0.007) (Table 3).

In women with GDM, there was a positive correlation between glucose with leukocytes $(r=0.70 ; p=0.03)$ on the one hand and between glucose with lymphocytes $(r=0.67 ; p=0.02)$ on the other hand (Table 4). Also, we noticed a positive correlation between serum triglycerides with monocytes $(r=0.87 ; p=0.045)$. In contrast, a negative correlation between granulocytes with HDL cholesterol was noted $(r=-0.90 ; p=0.026)$.

\section{Ratios of Immune Cells to Biochemical Parameters for Predicting GDM}

Table 5 shows ratios between immunological to biochemical parameters in women with GDM and pregnant controls. We found that ratios of lymphocytes/HDL-C, monocytes/HDL-C and granulocytes/HDL-C were significantly higher in women with GDM than in pregnant controls $(p=0.001 ; p=0.009$ and $p=0.004$ respectively).
A

Immune cell numbers in women with GDM $(n=25)$ and pregnant controls $(n=35)$

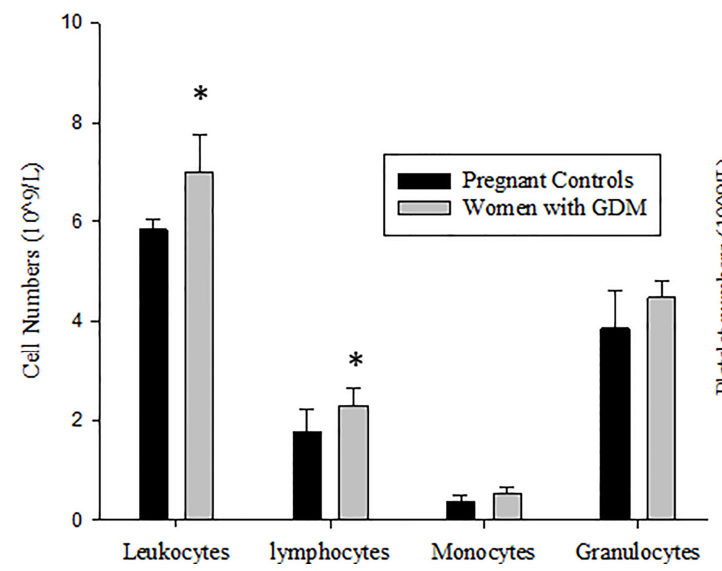

B

Platelet numbers in women with GDM $(n=25)$ and pregnant controls $(n=35)$

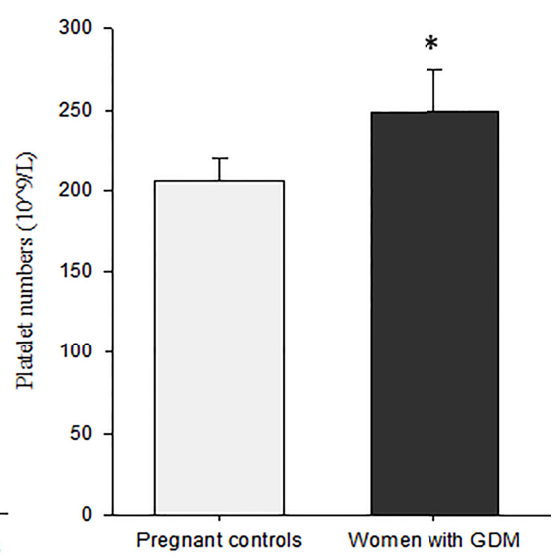

FIGURE 1 | Immune cell numbers in women with GDM $(n=25)$ and pregnant women without GDM as control group $(n=35):(A)$ total leukocytes, lymphocytes, monocytes and granulocytes; (B) Platelet numbers in women with GDM and pregnant controls. Values are means \pm SD. ${ }^{*} p$ values $(p<0.05)$ indicate significant difference between women with GDM and pregnant controls. Statistical analyses were performed using the Student's t-test or Mann-Whitney test. 


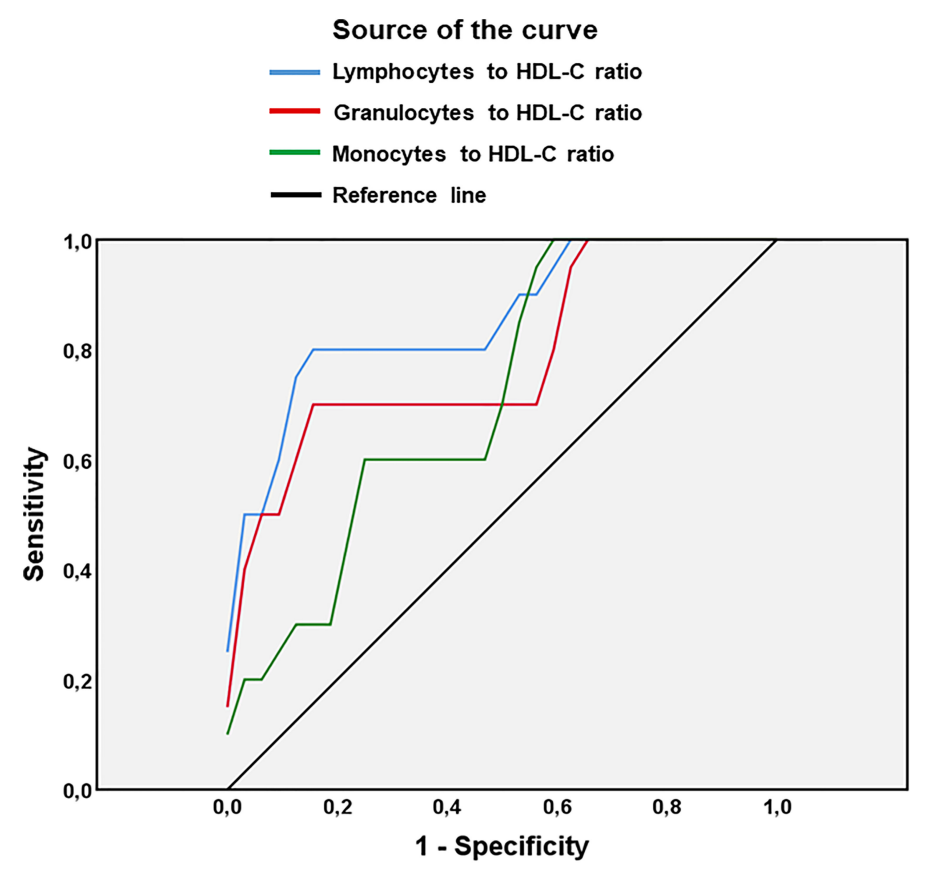

FIGURE 2 | Receiver Operating Characteristics (ROC) curve analysis of the value of ratios lymphocytes/HDL-C, granulocytes/HDL-C and monocytes/HDL-C for predicting gestational diabetes mellitus in pregnant women. HDL-C, high-density lipoprotein - cholesterol. $n=25$ women with GDM, $n=35$ pregnant women without GDM as control group.

TABLE 3 | Correlations between immune cell subpopulations and biochemical parameters in pregnant control women $(\mathrm{n}=35)$.

\begin{tabular}{|c|c|c|c|c|c|c|c|c|c|c|}
\hline \multirow[t]{2}{*}{ Immune cell subtypes } & \multicolumn{2}{|c|}{ Glucose } & \multicolumn{2}{|c|}{ TC } & \multicolumn{2}{|c|}{ HDL-C } & \multicolumn{2}{|c|}{ LDL-C } & \multicolumn{2}{|c|}{ TG } \\
\hline & $r$ & $\mathbf{p}$ & $r$ & $\mathbf{p}$ & $r$ & $\mathbf{p}$ & $r$ & $\mathbf{p}$ & $r$ & $\mathbf{p}$ \\
\hline Leucocytes & -0.50 & 0.45 & 0.37 & 0.22 & -0.19 & 0.46 & -0.42 & 0.09 & 0.37 & 0.24 \\
\hline Lymphocytes & 0.89 & $0.03^{*}$ & 0.50 & $0.04^{\star}$ & 0.36 & 0.17 & 0.11 & 0.68 & 0.16 & 0.73 \\
\hline Monocytes & -0.45 & 0.40 & -0.43 & 0.08 & -0.68 & $0.007^{\star}$ & 0.36 & 0.17 & 0.58 & $0.04^{*}$ \\
\hline Granulocytes & -0.81 & 0.07 & -0.27 & 0.30 & 0.22 & 0.39 & -0.25 & 0.35 & -027 & 0.39 \\
\hline Platelets & 0.68 & 0.08 & -0.33 & 0.20 & -0.36 & 0.18 & 0.20 & 0.45 & 0.33 & 0.27 \\
\hline
\end{tabular}

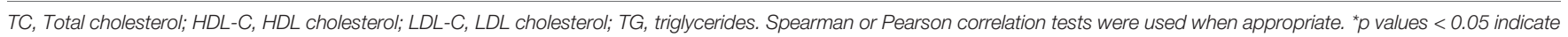
significant differences.

As shown in Figure 2, a ROC curve analysis was used to assess the accuracy, sensitivity, specificity and value of the ratios of lymphocytes/HDL-C, granulocytes/HDL-C and monocytes/ HDL-C for predicting GDM. The analysis showed that the lymphocytes/HDL-C ratio had a higher accuracy in predicting gestational diabetes mellitus (AUC $=0.859 ; p<0.001 ; 95 \% \mathrm{CI}$ : 0.752 - 0.966$)$ than the granulocytes/HDL-C ratio (AUC $=0.787 ; p<$ 0.01 ; $95 \%$ CI: $0.654-0.921$ ) or the monocytes/HDL-C ratio (AUC = $0.716 ; p<0.01 ; 95 \%$ CI: 0.576 - 0.855) (Table 6). The optimal cutoff values of lymphocytes/HDL-C ratio, granulocytes/HDL-C ratio and monocytes/HDL-C ratio for predicting GDM were, respectively, 3.66 (sensitivity $=80.0 \%$; specificity $=50.1 \%$ ); 5.50 $($ sensitivity $=70.3 \%$; specificity $=59.4 \%)$ and 1.56 (sensitivity $=$ $60.9 \%$; specificity $=50.0 \%$ ) (Table 6). Odds ratios were used to assess the risk of GDM. We observed that pregnant women with the lymphocytes/HDL-C ratio greater than 3.66 had a 4 -fold increased risk of developing GDM than those with lower ratios (odds ratio 4.00; 95\% CI: $1.094-14.630 ; p=0.041$ ) (Table 7).

\section{DISCUSSION}

Increasingly, the identification of biological parameters that can facilitate the prediction and early prognosis of gestational diabetes mellitus (GDM) has become a major concern for researchers. Given the complications associated with GDM in mothers, fetuses, newborns and adult offspring, an early diagnosis of GDM could help anticipate the care of pregnant women and limit the adverse effects. Therefore, the aim of this study was to investigate whether immunological parameters like immune cells, in conjunction with biochemical parameters, could be used to predict the risk of GDM. 
TABLE 4 | Correlations between immune cell subpopulations and biochemical parameters in women with GDM ( $\mathrm{n}=25)$.

\begin{tabular}{|c|c|c|c|c|c|c|c|c|c|c|}
\hline \multirow[t]{2}{*}{ Immune cell subtypes } & \multicolumn{2}{|c|}{ Glucose } & \multicolumn{2}{|c|}{ TC } & \multicolumn{2}{|c|}{ HDL-C } & \multicolumn{2}{|c|}{ LDL-C } & \multicolumn{2}{|c|}{ TG } \\
\hline & $r$ & $\mathbf{p}$ & $r$ & $\mathbf{p}$ & $r$ & $\mathbf{p}$ & $r$ & $\mathbf{p}$ & $r$ & $\mathbf{p}$ \\
\hline Leucocytes & 0.7 & $0.03^{*}$ & 0.20 & 0.76 & 0.66 & 0.26 & 0.61 & 0.30 & 0.21 & 0.76 \\
\hline Lymphocytes & 0.6 & $0.02^{*}$ & 0.12 & 0.99 & 0.81 & 0.13 & -0.12 & 0.95 & 0.16 & 0.95 \\
\hline Monocytes & -0.23 & 0.66 & 0.66 & 0.28 & 0.37 & 0.15 & 0.66 & 0.26 & 0.87 & $0.04^{*}$ \\
\hline Granulocytes & 0.72 & 0.23 & -0.48 & 0.5 & -0.9 & $0.02^{*}$ & -0.41 & 0.51 & -0.2 & 0.78 \\
\hline Platelets & -0.51 & 0.45 & 0.73 & 0.23 & 0.8 & 0.13 & 0.70 & 0.23 & 0.11 & 0.97 \\
\hline
\end{tabular}

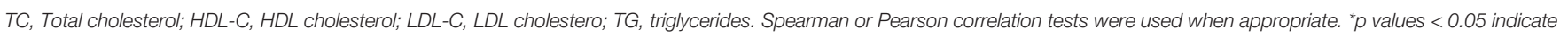
significant differences.

TABLE 5 | Ratios between immune cells to biochemical parameters in women with GDM $(n=25)$ and pregnant control women $(n=35)$.

\begin{tabular}{|c|c|c|c|}
\hline Variables & Pregnant control women $(n=35)$ & Women with GDM ( $n=25)$ & $p$-value \\
\hline Lymphocytes to Glucose ratio & $2.48 \pm 0.43$ & $2.03 \pm 0.59$ & 0.125 \\
\hline Lymphocytes to HDL-C ratio & $1.65 \pm 0.86$ & $7.38 \pm 3.21$ & $0.001^{\star}$ \\
\hline Lymphocytes to LDL-C ratio & $2.53 \pm 0.58$ & $1.62 \pm 0.22$ & 0.591 \\
\hline Lymphocytes to TG ratio & $1.50 \pm 0.27$ & $1.25 \pm 0.60$ & 0.469 \\
\hline Monocytes to Glucose ratio & $0.34 \pm 0.09$ & $0.47 \pm 0.13$ & 0.424 \\
\hline Monocytes to HDL-C ratio & $0.39 \pm 0.05$ & $1.73 \pm 0.49$ & $0.009^{*}$ \\
\hline Monocytes to LDL-C ratio & $0.41 \pm 0.27$ & $0.39 \pm 0.15$ & 0.701 \\
\hline Monocytes to TG ratio & $0.25 \pm 0.07$ & $0.34 \pm 0.09$ & 0.117 \\
\hline Granulocytes to Glucose ratio & $5.13 \pm 1.24$ & $3.33 \pm 0.73$ & 0.082 \\
\hline Granulocytes to HDL-C ratio & $3.55 \pm 2.02$ & $14.18 \pm 5.70$ & $0.004^{\star}$ \\
\hline Granulocytes to LDL-C ratio & $5.16 \pm 3.42$ & $3.27 \pm 0.95$ & 0.657 \\
\hline Granulocytes to TG ratio & $3.17 \pm 0.61$ & $2.91 \pm 0.73$ & 0.229 \\
\hline
\end{tabular}

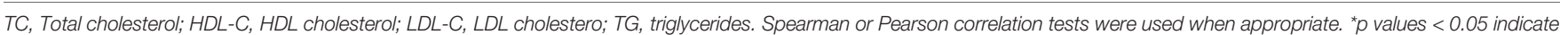
significant differences.

As far as metabolic aspect is concerned, diabetes is known to be associated with biochemical and metabolic disturbance (27). In the present study, we observed that HbA1C levels were normal and did not significantly differ between women with GDM and pregnant controls, although glycaemia remained high in women with GDM. The normal level of HbAlc might suggest that women with GDM were under an adequate metabolic control $(28,29)$. However, the fact that their glycemia remained high could suggest that women with GDM had poor glycemia control despite their normal HbA1c levels. In fact, it's important to note that pregnancy can impact $\mathrm{HbAlc}$ levels independently of glycemia. In a study conducted in pregnant women without GDM, it has been reported that the HbA1c level was low in early pregnancy and even more reduced at the end of pregnancy compared to non-pregnant women of the same age, suggesting that the pregnancy can significantly influence $\mathrm{HbAlc}$ levels regardless of glycemia (17). In addition, this dichotomy could also be explained by the fact that women with GDM are newly diagnosed and they have not yet been subjected to any anti-diabetic treatment $(28,29)$.

It is commonly believed that GDM is associated with the modulation of lipid profiles. Although the results describing lipid profiles during normal pregnancy and GDM are diverse and extensive, the results have been inconsistent $(15,17-20,30,31)$. The present study showed that serum TC, LDL-C and TG levels increased significantly, while HDL-C levels decreased in women with GDM compared to pregnant controls. These results are in agreement with others who have also shown a significant decrease in HDL levels in pregnant women with glucose intolerance compared to control women $(32,33)$. However, other studies have noted a significant rise in all lipids including HDL-C in women with GDM from the middle of the 2nd trimester of pregnancy to reach their peak at childbirth (34). A meta-analysis showed that GDM was associated with elevated serum TG in the 3rd trimester of pregnancy, while serum HDL-C levels were significantly low in the $2^{\text {nd }}$ and $3^{\text {rd }}$ trimesters (30). Indeed, during normal pregnancy, circulating lipids markedly increase, due to estrogen stimulation and insulin resistance (35). High maternal fat accumulation during pregnancy has also been shown to be associated with both overeating and increased fetal lipogenesis and energy demand, necessary for childbirth and lactation (27, 36-38). In GDM, the situation appears to be similar as lipid levels increased during pregnancy. In fact, the increased levels of TG, TC, and LDL$\mathrm{C}$ observed in GDM in the present study could lead to increased lipid storage in women with GDM, due to decreased lipolytic clearance of TG and increased hepatic lipase activity which appears to lead to increased HDL catabolism $(39,40)$.

As far as immunological aspects are concerned, there is evidence that gestational diabetes induces a profound variation of immune parameters (41). Indeed, we have recently demonstrated that GDM was associated with high frequencies of total CD3+ and CD4+ T lymphocytes and B cells, suggesting that GDM could induce a concomitant activation of cellular and humoral immunity (3). Likewise in the present study, we found that total leukocytes and lymphocytes in particular significantly increased in women with GDM as compared to control pregnant. There was no significant 
TABLE 6 | Areas Under the ROC Curve (AUC), Sensitivity and Specificity in predicting GDM.

\begin{tabular}{|c|c|c|c|c|}
\hline Risk factor & AUC $(95 \% \mathrm{Cl})$ & Cutoff According to Youden's Index & Sensitivity (\%) & Specificity (\%) \\
\hline Lymphocytes to HDL-C ratio & $0.859(0.752-0.966)$ & 3.66 & 80.0 & 50.1 \\
\hline Granulocytes to HDL-C ratio & $0.787(0.654-0.921)$ & 5.50 & 70.3 & 59.4 \\
\hline Monocytes to HDL-C ratio & $0.716(0.576-0.855)$ & 1.56 & 60.9 & 50.0 \\
\hline
\end{tabular}

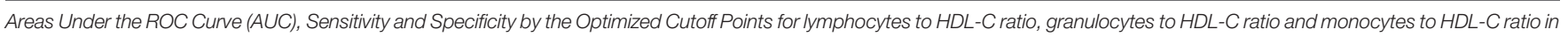
predicting GDM. ROC, Receiver operating characteristics; AUC, Area under ROC curve; Cl, Confidence interval.

TABLE 7 | Odds ratio (OR) of independent predictors accessing risk of gestational diabetes mellitus in women with GDM $(n=25)$ and pregnant control women $(n=35)$.

\begin{tabular}{lcc}
\hline Variable & OR (95\% Cl) & p-value \\
\hline Lymphocytes to HDL-C ratio & $4.000(1.094-14.630)$ & 0.041 \\
Granulocytes to HDL-C ratio & $1.596(0.486$ to 5.241$)$ & 0.557 \\
Monocytes to HDL-C ratio & $1.500(0.483-4.652)$ & 0.572 \\
\hline
\end{tabular}

difference in granulocyte and monocyte numbers in both groups of women. These results are in agreement with previous work which reported that increased inflammatory cellular markers were associated with impaired glucose metabolism, insulin resistance and GDM (42-44). Evidently, the increased numbers of leukocytes and lymphocytes in women with GDM were consistent with the increase of a wide range of inflammatory metabolic markers such as TG, TC and LDL-cholesterol which together lead to insulin resistance (42-44). In addition, we noticed a significant increase in the number of platelets in women with GDM compared to control women. These results were similar to those of Lim et al. (23) who have shown that high platelet numbers was associated with an increased prevalence and risk of metabolic syndrome in children and adolescents.

All these observations prompted us to investigate the correlations between immunological and metabolic parameters during GDM. In fact, we observed, in both pregnant controls as well as in women with GDM, a positive correlation between blood glucose and total lymphocytes, between TG and monocytes; between TC and lymphocytes in pregnant controls and between blood glucose and total leukocytes in women with GDM on the one hand. On the other hand, we found a negative correlation between HDL-cholesterol and monocytes in pregnant controls and between HDL-cholesterol and granulocytes in women with GDM. All these correlations suggested that these parameters could be useful in predicting GDM.

In order to determine whether both parameters could help in the prediction of GDM, we evaluated the ratios between immune cells (lymphocytes, granulocytes and monocytes) and biochemical parameters (glucose, TC, TG and LDL-C). Interestingly, we found that lymphocytes/HDL-C, monocytes/HDL-C, and granulocytes/ HDL-C ratios were significantly higher in women with GDM than in pregnant controls, suggesting that these ratios may certainly have significant value in predicting GDM. In fact, analysis of odds ratios indicated that only pregnant women with a lymphocytes/HDL-C ratio greater than 3.66 have a 4.0 -fold higher risk of developing GDM than those with a lymphocyte-to-HDL-C ratio lower (odds ratio 4.00; 95\% CI: $1,094-14,630 ; p=0.041$ ).
Moreover, we would like to highlight the role of HDL-C in the present results as this lipoprotein seems to represent a central parameter to which immune cell frequencies could be added to more reliably determine the pathogenesis of GDM. In fact, HDL-C, as an anti-atherogenic lipoprotein, is recognized as a protective factor in atherosclerosis and inflammation $(45,46)$. It has also been reported that TG/HDL-C ratio is a better marker for evaluating insulin resistance and diabetes (47). In addition, previous studies have shown that immune cells can be used as novel markers for predicting inflammation, metabolic syndromes, diabetes and atherosclerosis (48). Indeed, Pattanathaiyanon et al. (49) demonstrated that increased leucocyte numbers in early pregnancy may lead to a significant risk of GDM. Wolf et al. (50) have also previously reported that leucocyte numbers greater than 9100 cells/ $\mu \mathrm{L}$ in early pregnancy were significantly associated with a heightened risk of GDM.

To the best of our knowledge, our study is the first which analyzes the predictive power of immuno-biochemical markers in GDM, through ratios of lymphocytes, monocytes and granulocytes and HDL-C levels. Among these markers, the lymphocytes/HDL-C ratio seems to have a strong predictive power in the onset and development of GDM, and these parameters are easily accessible in patients. Even though the sample size was relatively small in this study, the causative effect of immune-metabolic biomarkers in GDM needs to be more investigated by including, in addition to immune cells, other inflammatory markers such as cytokines and chemokines. This aspect could be addressed in future investigations.

\section{CONCLUSION}

The present results constitute a major advance in the use of biological parameters for prediction of GDM. Immune cells associated with biochemical parameters appear as valuable markers which can allow to predict GDM. The interest of this study lies in the fact that these markers can be easily assessed on automatic devices which are usually found in medical analysis laboratories and that the interpretation of data is relatively simple. Pending future investigations that may involve other markers, we hope that the present results may be useful to clinicians and biologists specializing in the care of pregnant women.

\section{DATA AVAILABILITY STATEMENT}

The original contributions presented in the study are included in the article/Supplementary Material. Further inquiries can be directed to the corresponding author. 


\section{ETHICS STATEMENT}

The study was conducted in accordance with the Declaration of Helsinki 1964 (as revised in Edinburgh 2000) and was approved by the Ethics Committee on Research of the Institute of Applied Biomedical Sciences (CER-ISBA) of Cotonou, Benin under the number Dec.n ${ }^{\circ}$ 100/CER/ISBA-2016. Prior to enrollment, written consent was obtained from each participant who were informed of the study aim. The privacy rights of human subjects were observed. The patients/participants provided their written informed consent to participate in this study.

\section{AUTHOR CONTRIBUTIONS}

AF was in charge of major parts of technical aspects of work and participated in the manuscript writing. SF and MN participated in the technical work and participated in the interpretation of data. KM participated in the manuscript writing. AY designed the study, supervised the work, wrote the manuscript and established the collaborative aspects. All authors read and approved the final manuscript.

\section{REFERENCES}

1. Wang C, Zhu W, Wei Y, Su R, Feng H, Lin L, et al. The Predictive Effects of Early Pregnancy Lipid Profiles and Fasting Glucose on the Risk of Gestational Diabetes Mellitus Stratified by Body Mass Index. J Diabetes Res (2016) 2016:1-8. doi: 10.1155/2016/3013567

2. Kang X, Liang Y, Wang S, Hua T, Cui J, Zhang M, et al. Prediction Model Comparison for Gestational Diabetes Mellitus With Macrosomia Based on Risk Factor Investigation. J Matern Fetal Neonatal Med (2021) 34(15):248190. doi: 10.1080/14767058.2019.1668922

3. Fagninou A, Nekoua MP, Sossou D, Moutairou K, Fievet N, Yessoufou A. Th2-Immune Polarizing and Anti-Inflammatory Properties of Insulin Are Not Effective in Type 2 Diabetic Pregnancy. J Immunol. Res (2020) 2020: e2038746. doi: 10.1155/2020/2038746

4. Seshiah V, Das AK, Balaji V, Joshi SR, Parikh MN, Gupta S, et al. Gestational Diabetes Mellitus-Guidelines. J Assoc Physicians India (2006) 54:622-8. doi: 10.18203/2320-1770.ijrcog20151271

5. Kalra P, Kachhwaha CP, Singh HV. Prevalence of Gestational Diabetes Mellitus and its Outcome in Western Rajasthan. Indian J Endocrinol Metab (2013) 17:677-80. doi: 10.4103/2230-8210.113760

6. Jiwani A, Marseille E, Lohse N, Damm P, Hod M, Kahn JG. Gestational Diabetes Mellitus: Results From a Survey of Country Prevalence and Practices. J Matern Fetal Neonatal Med (2012) 25:600-10. doi: 10.3109/ 14767058.2011.587921

7. Eades CE, Cameron DM, Evans JMM. Prevalence of Gestational Diabetes Mellitus in Europe: A Meta-Analysis. Diabetes Res Clin Pract (2017) 129:17381. doi: 10.1016/j.diabres.2017.03.030

8. Lee KW, Ching SM, Ramachandran V, Yee A, Hoo FK, Chia YC, et al. Prevalence and Risk Factors of Gestational Diabetes Mellitus in Asia: A Systematic Review and Meta-Analysis. BMC Pregnancy Childbirth (2018) 18 (1):494. doi: 10.1186/s12884-018-2131-4

9. Ogurtsova K, da Rocha Fernandes JD, Huang Y, Linnenkamp U, Guariguata L, Cho NH, et al. IDF Diabetes Atlas: Global Estimates for the Prevalence of Diabetes for 2015 and 2040. Diabetes Res Clin Pract (2017) 128:40-50. doi: 10.1016/j.diabres.2017.03.024

10. England LJ, Dietz PM, Njoroge T, Callaghan WM, Bruce C, Buus RM, et al. Preventing Type 2 Diabetes: Public Health Implications for Women With a History of Gestational Diabetes Mellitus. Am J Obstet Gynecol (2009) 200:365.e1-8. doi: 10.1016/j.ajog.2008.06.031

\section{FUNDING}

This work did not receive any funding from any organization. The work was financed from the authors' own funds. Products and reagents were purchased by the contribution of the authors themselves.

\section{ACKNOWLEDGMENTS}

This work was carried out in the Laboratory of Cell Biology, Physiology and Immunology, Department of Biochemistry and Cellular Biology, Faculty of Sciences and Technology (FAST) and Institute of Applied Biomedical Sciences (ISBA), University of Abomey-Calavi (UAC), under the Ministry of Higher Education and Research of the Republic of Benin. The authors thank Ulbad Tougan, Casimir Ligan, Gabriel Assinon, and Keveen Yoclounon for their valuable technical advices and contributions. We also express our thanks and highly appreciate the contribution of Dr. Adrian J. F. Luty (Directeur de Recherche, MERIT UMR 261, IRD, Paris and Department of Medical Microbiology, Radboud University Nijmegen Medical centre, Nijmegen, The Netherland) for having carried out extensive proof reading of the manuscript and checked the English style.

11. Yang H, Wei Y, Gao X, Xu X, Fan L, He J, et al. Risk Factors for Gestational Diabetes Mellitus in Chinese Women-a Prospective Study of 16286 Pregnant Women in China. Diabetes Med (2000) 26:1099-104. doi: 10.1111/j.14645491.2009.02845.x

12. Hope O, Ifeanyi OE, Braxton N AQ. Investigation of Some Haematological Parameters in Pregnant Women With Gestational Diabetes at Federal Medical Center, Owerri, Imo State, Nigeria. Ann Clin Lab Res (2019) 7(n²:305):1-6.

13. Nekoua MP, Fachinan R, Atchamou AK, Nouatin O, Amoussou-Guenou D, Amoussou-Guenou MK, et al. Modulation of Immune Cells and Th1/Th2 Cytokines in Insulin-Treated Type 2 Diabetes Mellitus. Afr Health Sci (2016) 16:712. doi: 10.4314/ahs.v16i3.11

14. Nekoua MP, Fachinan R, Fagninou A, Alidjinou EK, Moutairou K, Hober D, et al. Does Control of Glycemia Regulate Immunological Parameters in Insulin-Treated Persons With Type 1 Diabetes? Diabetes Res Clin Pract (2019) 157:107868. doi: 10.1016/j.diabres.2019.107868

15. Ategbo J-M, Grissa O, Yessoufou A, Hichami A, Dramane KL, Moutairou K, et al. Modulation of Adipokines and Cytokines in Gestational Diabetes and Macrosomia. J Clin Endocrinol Metab (2006) 91:4137-43. doi: 10.1210/ jc.2006-0980

16. Seck A, Hichami A, Doucouré S, Diallo Agne F, Bassène H, Ba A, et al. Th1/ Th2 Dichotomy in Obese Women With Gestational Diabetes and Their Macrosomic Babies. J Diabetes Res (2018) 2018:1-7. doi: 10.1155/2018/ 8474617

17. Guermouche B, Yessoufou A, Soulimane N, Merzouk H, Moutairou K, Hichami A, et al. N-3 Fatty Acids Modulate T-Cell Calcium Signaling in Obese Macrosomic Rats. Obes Res (2004) 12:1744-53. doi: 10.1038/oby.2004.216

18. Soulimane-Mokhtari NA, Guermouche B, Yessoufou A, Saker M, Moutairou K, Hichami A, et al. Modulation of Lipid Metabolism by N-3 Polyunsaturated Fatty Acids in Gestational Diabetic Rats and Their Macrosomic Offspring. Clin Sci (2005) 109:287-95. doi: 10.1042/CS20050028

19. Yessoufou A, Soulaimann N, Merzouk SA, Moutairou K, Ahissou H, Prost J, et al. N-3 Fatty Acids Modulate Antioxidant Status in Diabetic Rats and Their Macrosomic Offspring. Int J Obes (2006) 30:739-50. doi: 10.1038/ sj.ijo.0803211

20. Yessoufou A, Moutairou K. Maternal Diabetes in Pregnancy: Early and LongTerm Outcomes on the Offspring and the Concept of "Metabolic Memory". Diabetes Res (2011) 2011:218598. doi: 10.1155/2011/218598

21. Akboga MK, Canpolat U, Sahinarslan A, Alsancak Y, Nurkoc S, Aras D, et al. Association of Serum Total Bilirubin Level With Severity of Coronary 
Atherosclerosis is Linked to Systemic Inflammation. Atherosclerosis (2015) 240:110-4. doi: 10.1016/j.atherosclerosis.2015.02.051

22. Balci KG, Balci MM, Sen F, Canpolat U, Akboga MK, Unal S, et al. The Role of Baseline Indirect Inflammatory Markers in Prediction of Response to Cardiac Resynchronisation Therapy. Kardiol Pol (2015) 2015:119-26. doi: 10.5603/ KP.a2015.0142

23. Lim H-J, Seo M-S, Shim J-Y, Kim K-E, Shin YH, Lee Y-J. The Association Between Platelet Count and Metabolic Syndrome in Children and Adolescents. Platelets (2015) 26:758-63. doi: 10.3109/09537104.2014.995613

24. Ertem AG, Yayla C, Acar B, Kirbas O, Unal S, Uzel Sener M, et al. Relation Between Lymphocyte to Monocyte Ratio and Short-Term Mortality in Patients With Acute Pulmonary Embolism. Clin Respir J (2018) 12:580-6. doi: 10.1111/crj.12565

25. IADPSG Consensus Panel. International Association of Diabetes and Pregnancy Study Groups (IADPSG) Recommendations on the Diagnosis and Classification of Hyperglycemia in Pregnancy. Diabetes Care (2010) 33:676-82. doi: $10.2337 / \mathrm{dc} 09-1848$

26. Benlian P, Béréziat G. Revue Française Des Laboratoires - Présentation - EM Consulte.Html Vol. 2001. Paris: Revue Française des Laboratoires, Edition. Paris: Elsevier Masson SAS (2001) p. 68-9. doi: 10.1016/S0338-9898(01)80058-5

27. Mankuta D, Elami-Suzin M, Elhayani A, Vinker S. Lipid Profile in Consecutive Pregnancies. Lipids Health Dis (2010) 9:58. doi: 10.1186/1476-511X-9-58

28. Mahmoud F, Abul H, Omu A, Haines D. Lymphocyte Sub-Populations in Gestational Diabetes. Am J Reprod Immunol (2005) 53:21-9. doi: 10.1111/j.1600-0897.2004.00241.x

29. Viardot A, Grey ST, Mackay F, Chisholm D. Potential Antiinflammatory Role of Insulin via the Preferential Polarization of Effector T Cells Toward a T Helper 2 Phenotype. Endocrinology (2007) 148:346-53. doi: 10.1210/en.2006-0686

30. Ryckman K, Spracklen C, Smith C, Robinson J, Saftlas A. Maternal Lipid Levels During Pregnancy and Gestational Diabetes: A Systematic Review and Meta-Analysis. BJOG Int J Obstet Gynaecol (2015) 122:643-51. doi: 10.1111/ 1471-0528.13261

31. Shen H, Liu X, Chen Y, He B, Cheng W. Associations of Lipid Levels During Gestation With Hypertensive Disorders of Pregnancy and Gestational Diabetes Mellitus: A Prospective Longitudinal Cohort Study. BMJ (2016) 6: e013509. doi: 10.1136/bmjopen-2016-013509

32. Aziz R, Mahboob T. Lipid Profile and Serum Insulin Levels in Gestational Diabetes. J Dow Univ Health Sci JDUHS (2008) 2:101-6.

33. Suresh E, Prasad G. Study of Biochemical Changes in Gestational Diabetes Mellitus. Int J Appl Res (2017) 3:03-8.

34. Herrera Martínez A, Palomares Ortega R, Bahamondes Opazo R, MorenoMoreno P, Molina Puerta M-J, Gálvez-Moreno A. Hyperlipidemia During Gestational Diabetes and Its Relation With Maternal and Offspring Complications. Nutr Hosp (2018) 35(3):698-706. doi: 10.20960/nh.1539

35. Butte NF. Carbohydrate and Lipid Metabolism in Pregnancy: Normal Compared With Gestational Diabetes Mellitus. Am J Clin Nutr (2000) 71:1256S-61S. doi: 10.1093/ajcn/71.5.1256s

36. Murphy SP, Abrams BF. Changes in Energy Intakes During Pregnancy and Lactation in a National Sample of US Women. Am J Public Health (1993) 83:1161-3. doi: 10.2105/AJPH.83.8.1161

37. Di Cianni G, Miccoli R, Volpe L, Lencioni C, Ghio A, Giovannitti MG, et al. Maternal Triglyceride Levels and Newborn Weight in Pregnant Women With Normal Glucose Tolerance. Diabetes Med (2005) 22:21-5. doi: 10.1111/j.14645491.2004.01336.x

38. Ghio A, Bertolotto A, Resi V, Volpe L, Di Cianni G. Triglyceride Metabolism in Pregnancy. Adv Clin. Chem (2011) 55:133-53. doi: 10.1016/B978-0-12387042-1.00007-1

39. Herrera E, Lasunción MA, Gomez-Coronado D, Aranda P, López-Luna P, Maier I. Role of Lipoprotein Lipase Activity on Lipoprotein Metabolism and the Fate of Circulating Triglycerides in Pregnancy. Am J Obstet Gynecol (1988) 158:1575-83. doi: 10.1016/0002-9378(88)90193-7
40. Meyer BJ, Stewart FM, Brown EA, Cooney J, Nilsson S, Olivecrona G, et al. Maternal Obesity Is Associated With the Formation of Small Dense LDL and Hypoadiponectinemia in the Third Trimester. J Clin Endocrinol Metab (2013) 98:643-52. doi: 10.1210/jc.2012-3481

41. Siddiqui S, Waghdhare S, Jhaa S, Dubey S. Role of Immunological Markers in Gestational Diabetes Mellitus-A Brief Review. Diabetes Metab Syndr (2019) 13 (5):2983-5. doi: 10.1016/j.dsx.2018.07.018

42. Kim S, Nguon C, Guillard B, Duong S, Chy S, Sum S, et al. Performance of the CareStart ${ }^{\mathrm{TM}}$ G6PD Deficiency Screening Test, a Point-of-Care Diagnostic for Primaquine Therapy Screening. PloS One (2011) 6:e28357. doi: 10.1371/ journal.pone.0028357

43. Demirtas L, Degirmenci H, Akbas EM, Ozcicek A, Timuroglu A, Gurel A, et al. Association of Hematological Indicies With Diabetes, Impaired Glucose Regulation and Microvascular Complications of Diabetes. Int J Clin Exp Med (2015) 8:11420-7.

44. Yılmaz ZV, Yılmaz E, İçer B, Küçüközkan T. Association of Complete Blood Count Parameters With Gestational Diabetes Mellitus. Gynecol Obstet Reprod Med (2016) 23:1-5. doi: 10.21613/GORM.2016.649

45. Murphy AJ, Woollard KJ, Hoang A, Mukhamedova N, Stirzaker RA, McCormick SPA, et al. High-Density Lipoprotein Reduces the Human Monocyte Inflammatory Response. Arterioscler Thromb Vasc Biol (2008) 28:2071-7. doi: 10.1161/ATVBAHA.108.168690

46. Rohatgi A. High-Density Lipoprotein Function Measurement in Human Studies: Focus on Cholesterol Efflux Capacity. Prog Cardiovasc Dis (2015) 58:32-40. doi: 10.1016/j.pcad.2015.05.004

47. Lin D, Qi Y, Huang C, Wu M, Wang C, Li F, et al. Associations of Lipid Parameters With Insulin Resistance and Diabetes: A Population-Based Study. Clin Nutr (2018) 37:1423-9. doi: 10.1016/j.clnu.2017.06.018

48. Chen T, Chen H, Xiao H, Tang H, Xiang Z, Wang X, et al. Comparison of the Value of Neutrophil to High-Density Lipoprotein Cholesterol Ratio and Lymphocyte to High-Density Lipoprotein Cholesterol Ratio for Predicting Metabolic Syndrome Among a Population in the Southern Coast of China. Diabetes Metab Syndr Obes Targets Ther (2020) 13:597-605. doi: 10.2147/ DMSO.S238990

49. Pattanathaiyanon P, Phaloprakarn C, Tangjitgamol S. Comparison of Gestational Diabetes Mellitus Rates in Women With Increased and Normal White Blood Cell Counts in Early Pregnancy: White Blood Cells and Gestational Diabetes. J Obstet Gynaecol Res (2014) 40:976-82. doi: 10.1111/ jog. 12306

50. Wolf M, Sandler L, Hsu K, Vossen-Smirnakis K, Ecker JL, Thadhani R. FirstTrimester C-Reactive Protein and Subsequent Gestational Diabetes. Diabetes Care (2003) 26:819-24. doi: 10.2337/diacare.26.3.819

Conflict of Interest: The authors declare that the research was conducted in the absence of any commercial or financial relationships that could be construed as a potential conflict of interest.

Publisher's Note: All claims expressed in this article are solely those of the authors and do not necessarily represent those of their affiliated organizations, or those of the publisher, the editors and the reviewers. Any product that may be evaluated in this article, or claim that may be made by its manufacturer, is not guaranteed or endorsed by the publisher.

Copyright $\odot 2022$ Fagninou, Nekoua, Fiogbe, Moutairou and Yessoufou. This is an open-access article distributed under the terms of the Creative Commons Attribution License (CC BY). The use, distribution or reproduction in other forums is permitted, provided the original author(s) and the copyright owner(s) are credited and that the original publication in this journal is cited, in accordance with accepted academic practice. No use, distribution or reproduction is permitted which does not comply with these terms. 